\title{
The Influence of Charge Trapping on the Electrochromic Performance of Poly(3,4-alkylenedioxythiophene) Derivatives
}

\author{
Jen-Hsien Huang, ${ }^{\dagger}$ Chih-Yu Hsu, ${ }^{\mp}$ Chih-Wei Hu, ${ }^{\S}$ Chih-Wei Chu, ${ }^{*}{ }^{\dagger, \perp}$ and Kuo-Chuan Ho*, ${ }^{*}, \S$ \\ Research Center for Applied Sciences, Academia Sinica, Taipei, Taiwan 11529, Department of Chemical \\ Engineering and Institute of Polymer Science and Engineering, National Taiwan University, Taipei, Taiwan 10617, \\ and Department of Photonics, National Chiao-Tung University, Hsinchu, Taiwan 30010
}

\begin{abstract}
This paper describes the electrochromic properties of a series of poly(3,4-alkylenedioxythiophene) (PXDOT) derivatives featuring various ring sizes and substitutions. The presence of a bulky group on the monomer resulted in a polymer possessing a more-open morphology, which promoted reversible ionic transfer. We used an electrochemical quartz crystal microbalance and cyclic voltammetry to investigate the properties of these polymers. We found that both cations and anions were involved in the charge compensation process. Furthermore, PXDOT derivatives possessing larger ring sizes and/or longer alkyl substituents exhibited less trapping of ions within the polymer during the redox process. The long-term electrochromic stability of these PXDOTs depended strongly on the number of trapped ions. Although the transmittance attenuation of poly(3,4-ethylenedioxythiophene) (PEDOT) decreased from 53 to $42 \%$, we observed no significant decay for poly(diethyl-3,4-dihydro-2H-thieno[3,4-b]-[1,4]dioxepine) (PProDOT$\mathrm{Et}_{2}$ ) after 400 cycles
\end{abstract}

KEYWORDS: electrochromic $\bullet$ conjugated polymer $\bullet$ PXDOT $\bullet$ ionic transport $\bullet$ EQCM $\bullet$ stability

\section{INTRODUCTION}

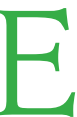
lectrochromic materials exhibit reversible and visible changes in their optical absorptions in response to changes in potential. Electrochromic techniques are employed in many applications in the optical, communications, construction, and automobile industries and in the military $(1-3)$. Great efforts have been made over the last two decades to study the oxides of many transition metals (4-6) for their electrochromic behavior. These materials are, however, very expensive to process and their small coloration efficiencies and slow response times inevitably limit their commercial and industrial applications (7-9). Organic materials comprise a family of electrochromic materials that are of interest because of their ready color tuning, large coloration efficiencies, high electrochromic contrasts (10), and rapid response times (11). Among candidate organic materials, poly(3,4-ethylenedioxythiophene) (PEDOT) and its derivatives have been investigated most often because of their low oxidation potentials, high coloring efficiencies, and increased stabilities in their doped forms at ambient and elevated temperatures $(12-24)$. PEDOT is a cathodically coloring polymer that is dark opaque blue in its reduced state

\footnotetext{
*Corresponding author. E-mail: kcho@ntu.edu.tw (K.-C.H); gchu@ gate.sinica.edu.tw (C.-W.C.). Tel.: +886-2-23660739 (K.-C.H); +886-2-27898000 (C.-W.C.). Fax: +886-2-23623040 (K.-C.H); +886-2-27826680 (C.-W.C.)

Received for review May 4, 2009 and accepted January 5, 2010

+ Academia Sinica.

* Department of Chemical Engineering, National Taiwan University.

$\S$ Institute of Polymer Science and Engineering, National Taiwan University.

${ }^{\perp}$ National Chiao-Tung University.

DOI: $10.1021 / \mathrm{am} 900752 \mathrm{~m}$

( 2010 American Chemical Society
}

and a very transmissive light blue in its oxidized state; it offers $44 \%$ contrast, measured at $590 \mathrm{~nm}$, between its reduced $(-1.0 \mathrm{~V})$ and oxidized $(1.0 \mathrm{~V})$ states $(25)$. Other than the coloration efficiency, the life cycle of an electrochromic material is another important factor when considering practical applications. A major obstacle to the commercialization of conducting polymers, however, is their relatively poor cycle life (26-28). Although the presence of water/ moisture in electrolytes or during the fabrication of polymers can decrease the performance and long-term stability of electrochromics $(29,30)$, the improvements in stability under fully dry processing conditions have not been sufficient to promote their practical application. The major degradation mechanism remains poorly explored.

In this study, we investigated the relationship between the chemical structure of the polymer and its electrochromicity. We used an electrochemical quartz crystal microbalance (EQCM) to characterize the polymers prepared from various monomers. Quantitative analysis was performed using EQCM combined with cyclic voltammetry $(\mathrm{CV})$ to investigate the ion transfer occurring within the polymer during the charge compensation process. We found that ion pairs were trapped in the polymer films during the redox process. Modifying the structure of the polymer with larger ring sizes and longer substituents led to more-porous morphologies, resulting in smaller numbers of trapped ions and greater long-term stability.

\section{EXPERIMENTAL SECTION}

The chemical structures of 3,4-ethylenedioxythiophene (EDOT), 3,4-propylenedioxythiophene (ProDOT), 3,3-dimethyl3,4-dihydro- $2 \mathrm{H}$-thieno[3,4-b]-[1,4]dioxepine (ProDOT- $\mathrm{Me}_{2}$ ), and 
Scheme 1. Chemical Structures of EDOT, ProDOT, ProDOT- $\mathrm{Me}_{2}$, and ProDOT-Et

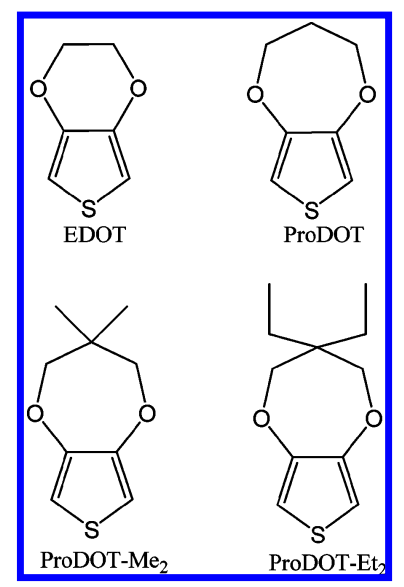

diethyl-3,4-dihydro-2H-thieno[3,4-b]-[1,4]dioxepine (ProDOT$\left.\mathrm{Et}_{2}\right)$ are presented in Scheme 1. These so-called XDOTs were all purchased from Aldrich. Acetonitrile (ACN, TEDIA) was dried with molecular sieves ( $4 \AA$, Acros) prior to use. Polymerization

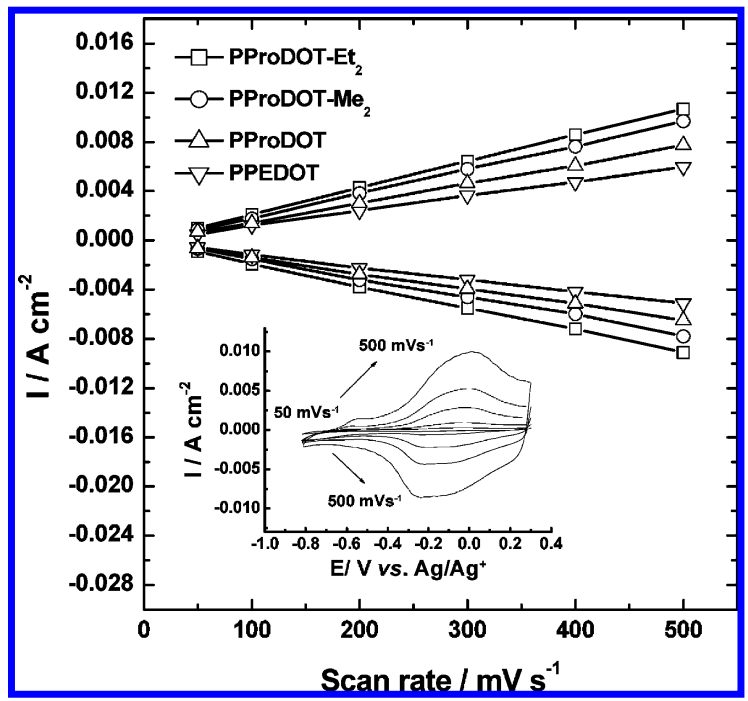

FIGURE 2. Plots of current density versus scan rate for the PXDOTs under $0.1 \mathrm{M} \mathrm{LiClO}_{4} / \mathrm{DMF}$. Inset: $\mathrm{CV}$ traces for PProDOT-Et ${ }_{2}$ at various potential scan rates.
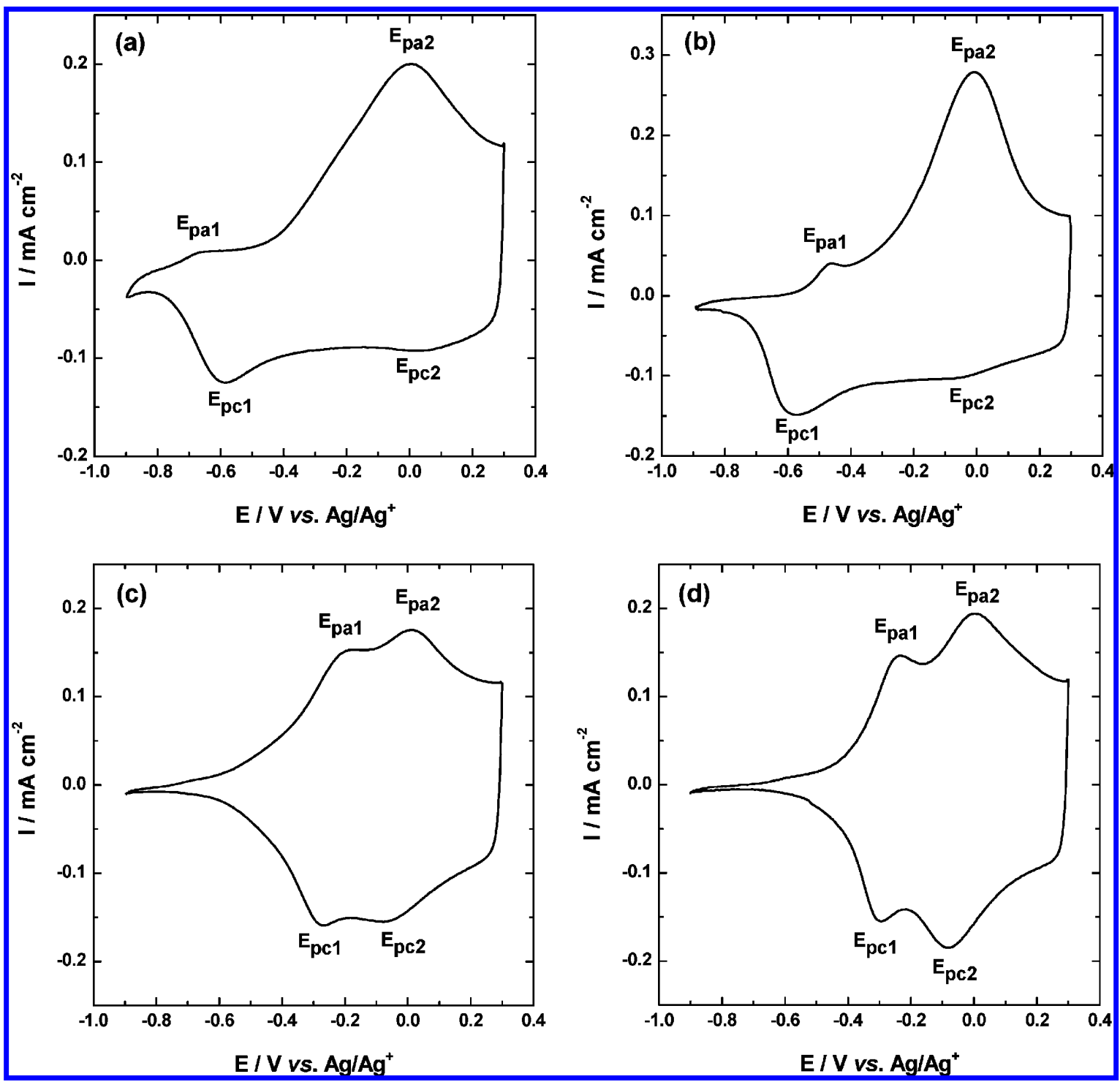

FIGURE 1. Cyclic voltammograms of PXDOTs [vs Ag/Ag $\left.{ }^{+}(\mathrm{ACN})\right]$ in $0.1 \mathrm{M} \mathrm{LiClO}_{4} / \mathrm{DMF}$ : (a) PEDOT, (b) PProDOT, (c) PProDOT-Me 2 , (d) PProDOT$\mathrm{Et}_{2}$. Scan rate: $50 \mathrm{mV} \mathrm{s}^{-1}$. 


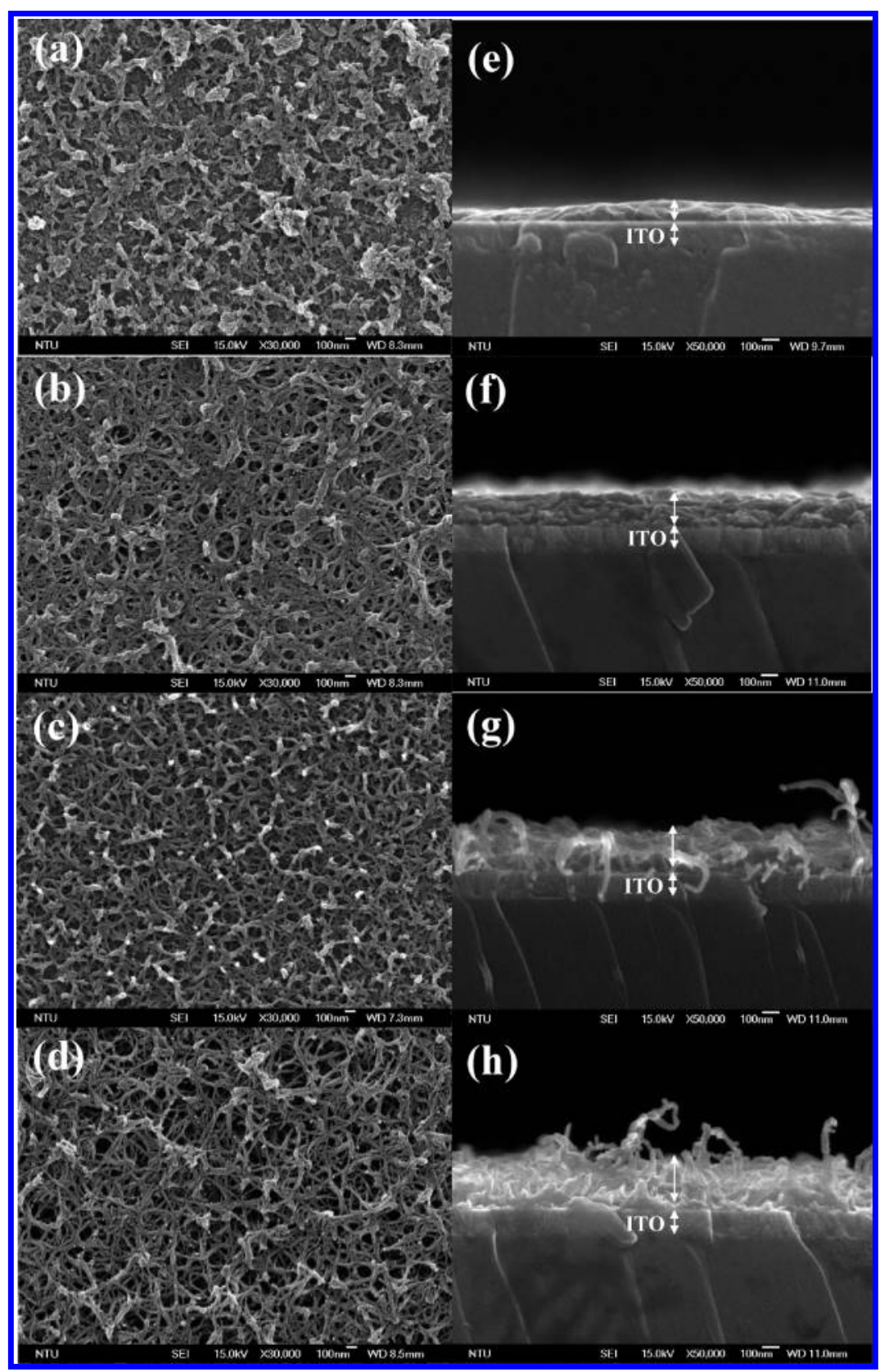

FIGURE 3. SEM micrographs of films of (a) PEDOT, (b) PProDOT, (c) PProDOT-Me ${ }_{2}$, and (d) PProDOT-Et 2.

experiments were performed in a three-electrode electrochemical cell possessing a Pt foil counter electrode and a Ag/ $\mathrm{Ag}^{+}$ reference electrode $\left(0.01 \mathrm{M} \mathrm{AgNO}_{3}\right.$ and $0.1 \mathrm{M} \mathrm{TBAClO}_{4}$ in $\left.\mathrm{ACN}\right)$. Optically transparent indium tin oxide (ITO) glass substrates $\left(R_{\mathrm{sh}}\right.$ $=20 \Omega \mathrm{sq}^{-1}$ ), used as working electrodes, were supplied by RiTdisplay Corporation (Hsinchu Industrial Park, Taiwan). The ITO glass substrates $\left(2 \times 2 \mathrm{~cm}^{2}\right)$ were cleaned ultrasonically in $0.1 \mathrm{M} \mathrm{HCl}$ for $3 \mathrm{~min}$ and then rinsed with deionized water for another $3 \mathrm{~min}$. The monomer solution contained 0.01 M EDOT (or one of its derivatives) in $0.1 \mathrm{M} \mathrm{LiBF}_{4} / \mathrm{ACN}$. The deposition of the PXDOTs was controlled using an Autolab PGSTAT30 potentiostat/galvanostat (Eco Chemie). The polymer thin films were electropolymerized onto the ITO glass substrates by applying a potential at $1.1 \mathrm{~V}$ with a charge capacity of $20 \mathrm{mC}$ $\mathrm{cm}^{-2}$. CV studies were performed using a three-electrode cell containing $0.1 \mathrm{M} \mathrm{LiClO}_{4} / \mathrm{ACN}$ and ITO as the working electrode, a Pt sheet as the counter electrode, and nonaqueous $\mathrm{Ag} / \mathrm{Ag}^{+}$ (containing $0.01 \mathrm{M} \mathrm{AgNO}_{3}$ and $0.1 \mathrm{M} \mathrm{TBAClO}_{4}$ in $\mathrm{ACN}$ ) as the reference electrode. Spectroelectrochemical data were recorded using a Shimadzu model UV-1601 PC spectrophotometer. EQCM investigations were performed using a quartz crystal analyzer (Seiko EG\&G, QCA917) connected to the Autolab potentiostat/ galvanostat. The substrate electrodes used for EQCM were Pt electrodes $\left(0.196 \mathrm{~cm}^{2}\right)$ coated on an AT-cut quartz crystal ( 9 $\mathrm{MHz}$, Seiko EG\&G). The mass changes per active area were calculated using the Sauerbrey equation (31)

$$
\Delta m=\frac{\left(N r_{\mathrm{q}}\right)}{f_{0}^{2}} \Delta f
$$

where $N$ is the shear modulus of quartz $(167 \mathrm{kHz} \cdot \mathrm{cm}), r_{\mathrm{q}}$ is the density of the crystal $\left(2.684 \mathrm{~g} \mathrm{~cm}^{-3}\right), f_{0}$ is the resonance frequency of the fundamental mode of the crystal $(8.88 \mathrm{MHz})$, and $\Delta f$ is the resonance frequency shift during redox cycling. The sensitivity of the EQCM apparatus was $5.608 \mathrm{ng} \mathrm{Hz}^{-1}$. X-ray photoelectron spectroscopy (XPS) was performed using a PHI 5000 VersaProbe (ULVAC-PHI, Chigasaki, Japan) system. The polymer films were prepared through electrochemical deposi- 
tion and CV cycling in a three-electrode system, as described in the EQCM section. They were then washed with ACN and dried in a vacuum.

\section{RESULTS AND DISCUSSION}

Figure 1 presents the CV results for the PXDOT derivatives in $0.1 \mathrm{M} \mathrm{LiClO}_{4} / \mathrm{N}, \mathrm{N}$-dimethylformamide (DMF). The traces for all of the polymers revealed two coupled redox peaks between 0.3 and $-0.9 \mathrm{~V}$. For example, PEDOT was reduced at 0.04 and $-0.58 \mathrm{~V}$ during cathodic scans. These multiple reductions might have been due to the sequential reductions of bipolaronic and polaronic charge carriers (32). Although the CV behavior of PEDOT and PProDOT was very similar, the anodic $\left(I_{\mathrm{a}}\right)$ and cathodic $\left(I_{\mathrm{p}}\right)$ currents of PProDOT were larger than those of PEDOT. As expected, different ring sizes and substitution affected the physical properties of the polymers. When we increased the ring size from two to three carbon atoms (i.e., from PEDOT to PProDOT), the resulting polymer featured a more porous morphology, which facilitated the migration of cations and anions, resulting in larger values of $I_{\mathrm{a}}$ and $I_{\mathrm{C}}(19,25)$. On the other hand, the CV trace of PProDOT- $\mathrm{Me}_{2}$ revealed quite distinct features relative to that of PProDOT, due to the methyl substituents positioned below and above the plane of the $\pi$-conjugated backbone repressing $\pi$-stacking. Consequently, the crystalline structures of PEDOT and PProDOT, resulting from intermolecular interactions between oxygen atoms and adjacent thienyl hydrogen atoms, were destroyed, leading to the completely different CV behavior of PProDOT-Me 2 (33). For similar reasons, larger values of $I_{\mathrm{a}}$ and $I_{\mathrm{c}}$ of PProDOT-Et $\mathrm{t}_{2}$ resulted from the more-open structure formed when the length of the substituent increased from methyl to ethyl. Such an effect has been observed previously for other XDOTs substituted with bulky groups (34). From the CV results, we calculated the doping levels $(R)$ of our four polymers using the equation (35)

$$
R=2 Q_{\mathrm{a}} / Q_{\mathrm{d}}
$$

where $Q_{\mathrm{a}}$ and $Q_{\mathrm{d}}$ are the anodic and polymeric charges, respective. The factor of 2 was derived from the generally accepted mechanism for oxidative electropolymerization, where two electrons are transferred for each monomer unit incorporated into the polymer chain (36). PEDOT, PProDOT, PProDOT- $-\mathrm{Me}_{2}$, and PProDOT-Et 2 had doping levels of 19.5, $20.6,21.3$, and $23.1 \%$, respectively; these values are very close to those from a previous report (37). The relatively larger doping levels of PProDOT-Me $\mathrm{M}_{2}$ and PProDOT-Et resulted from their open morphologies, which allowed larger ions to be inserted or extracted during the redox reaction. Therefore, the presence of bulky substituents on the XDOT ring decreases the internal pressure of the doped polymer caused by insertion of counterions during electrochemical doping. This phenomenon allows for a higher doping level and, therefore, greater charge transfer $(33,35)$. Figure 2 displays the variation of the current density of PXDOTs upon increasing the scan rate up to $500 \mathrm{mV} \mathrm{s}^{-1}$; we observe a linear relationship between the peak current and scan rate

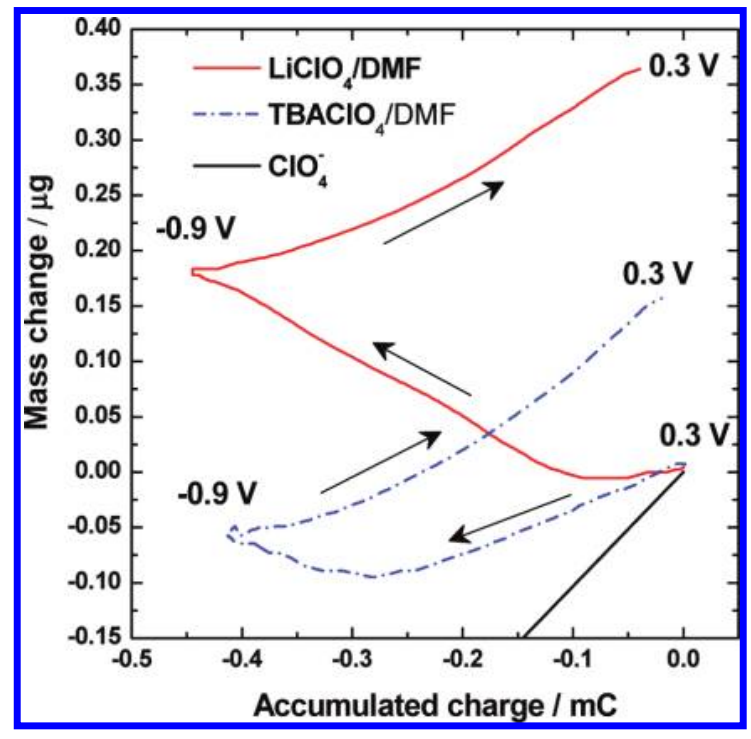

FIGURE 4 . Plots of $\Delta m$ versus $\Delta Q$ for PEDOT cycled between -0.9 and $0.3 \mathrm{~V}$ [vs $\left.\mathrm{Ag} / \mathrm{Ag}^{+}(\mathrm{ACN})\right]$ in $0.1 \mathrm{M} \mathrm{LiClO}_{4} / \mathrm{DMF}$ (red) and $0.1 \mathrm{M}$ $\mathrm{TBAClO}_{4} / \mathrm{DMF}$ (black). Scan rate: $50 \mathrm{mV} \mathrm{s}^{-1}$. The blue dashed line is the theoretical result obtained when only $\mathrm{ClO}_{4}{ }^{-}$transfer is considered.

in each case, suggesting the formation of well-adhered electroactive polymer films on the electrodes and that the electrochemical processes were reaction-controlled. Moreover, for all of the polymers, we observed near-linear increases in the anodic peak potentials upon increasing the scan rate (data shown only for PProDOT-Et - $_{2}$ see the inset to Figure 2), suggesting that the redox processes were not reversible, but rather followed a quasi-reversible mechanism.

Figure 3 presents scanning electron microscopy (SEM) images of the PXDOT films. These PXDOT films became increasingly porous upon increasing the ring size and/or the length of the side chains (Figure $3 a-d)$. It is likely that the alkyl chains separate the conjugated backbones from each other, leading to significantly different structures (38). Surprisingly, PProDOT-Et $t_{2}$ featured a nanofiber-shaped structure (nanofiber diameter: 10-20 nm), which increased the specific surface area significantly. The presence of a bulky group on the monomer resulted in less-dense polymer films that facilitated movement of counterions and resulted in larger values of $I_{\mathrm{a}}$ and $I_{\mathrm{p}}$. The SEM images are in good agreement with the CV data. Furthermore, the crosssectional SEM images of the PXDOTs reveal the presence of two interfaces: one between the glass substrate and ITO and the other between ITO and the polymer film. The film thicknesses of PEDOT, PProDoT, PProDOT-Me 2 , and PProDOT-Et 2 were ca. 100, 150, 220, and $260 \mathrm{~nm}$, respectively. Although these polymer films were all fabricated under the same conditions, the film thicknesses increased upon forming looser structures.

To study the ionic exchange processes occurring in PXDOT films prepared through electrodeposition, we performed their analysis using a combination of EQCM and CV. Prior to EQCM characterization, it is necessary to determine whether anions and cations were involved in the redox process. During the synthesis of the PXDOTs, a potential of 1.2 $\mathrm{V}$ was obtained, meaning that anions had to be inserted 

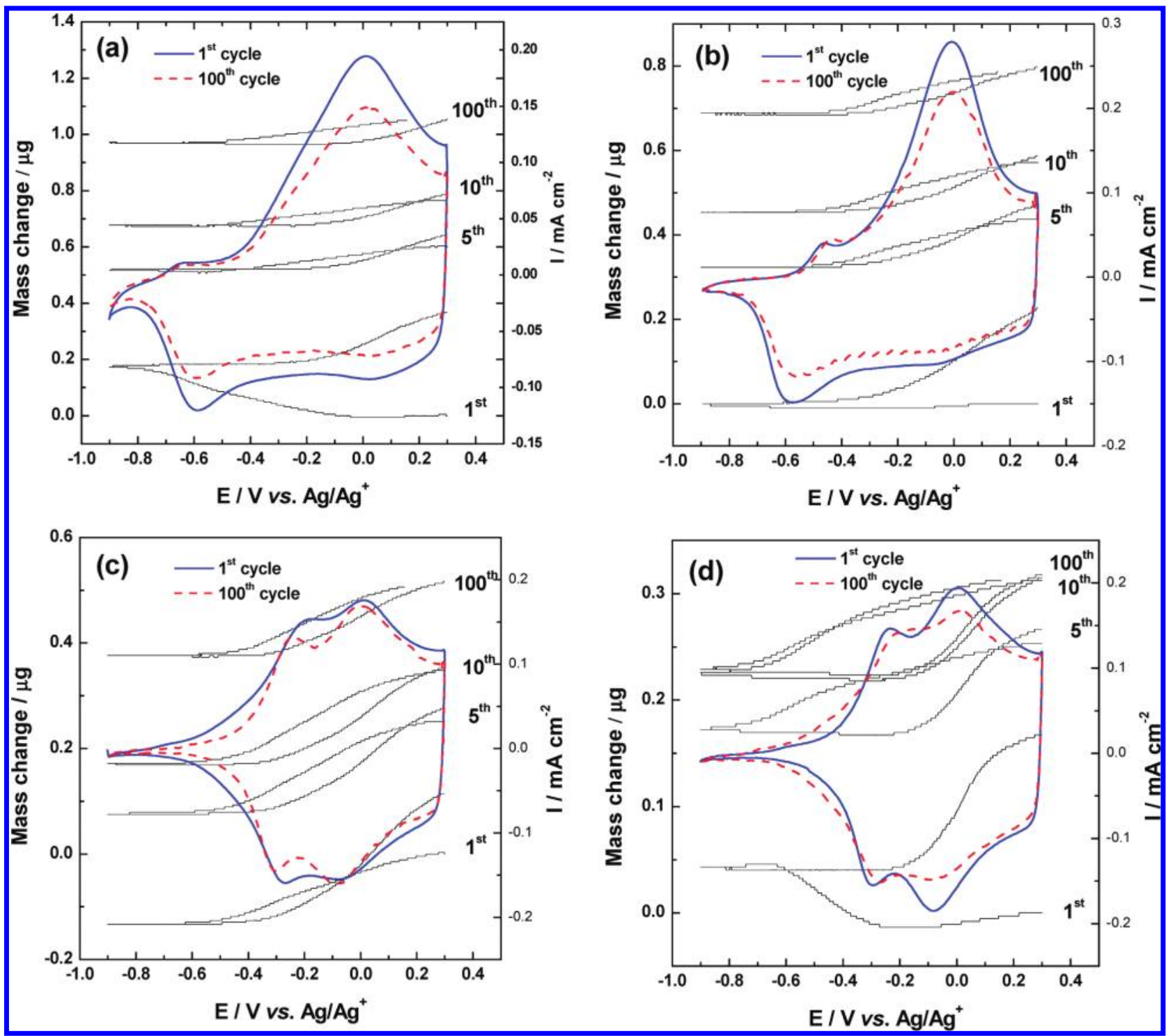

FIGURE 5. EQCM (left axis) and CV (right axis) responses of the polymers (a) PEDOT, (b) PProDOT, (c) PProDOT-Me ${ }_{2}$, and (d) PProDOT-Et ${ }_{2}$ in $0.1 \mathrm{M} \mathrm{LiClO}_{4} / \mathrm{DMF}$.

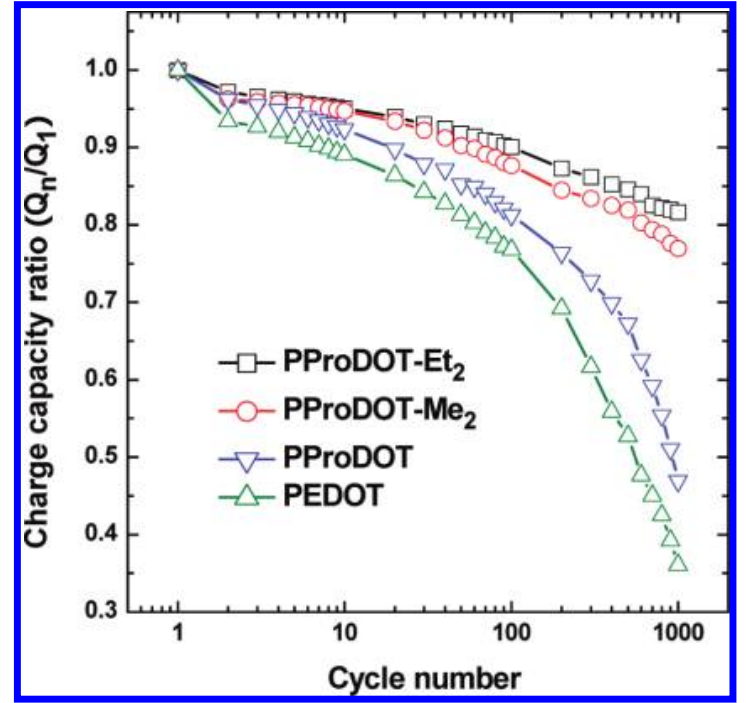

FIGURE 6. Variations in charge capacities of PXDOTs as a function of the cycle number in $\mathrm{LiClO}_{4} / \mathrm{DMF}$. CV scanning was performed from 0.3 to $-0.9 \mathrm{~V}$ at a scan rate of $50 \mathrm{mV} \mathrm{s}^{-1}$. into the polymer films to maintain a neutral state. Therefore, we performed our EQCM analysis to study the influence of cations only in $0.1 \mathrm{M} \mathrm{LiClO}_{4}$ and $\mathrm{TBAClO}_{4} / \mathrm{DMF}$ (Figure 4). At the beginning of the reduction process using $\mathrm{TBAClO}_{4} /$ DMF, we observed a rapid diminution of mass, indicating that ejection of anions was the predominant process. In the case of $\mathrm{LiClO}_{4} / \mathrm{DMF}$, however, the reduction process was accompanied by an increase in mass, suggesting that electroneutralization of the film had occurred through the participation of cations. The straight line in Figure 4 is a theoretical curve obtained when assuming that $\mathrm{ClO}_{4}{ }^{-}$is the only species maintaining the charge compensation in the films of the PEDOT derivatives; it was calculated using the Sauerbrey equation (31)

$$
\Delta m=\frac{W_{\mathrm{ClO}_{4}^{-}}}{F} \Delta Q
$$



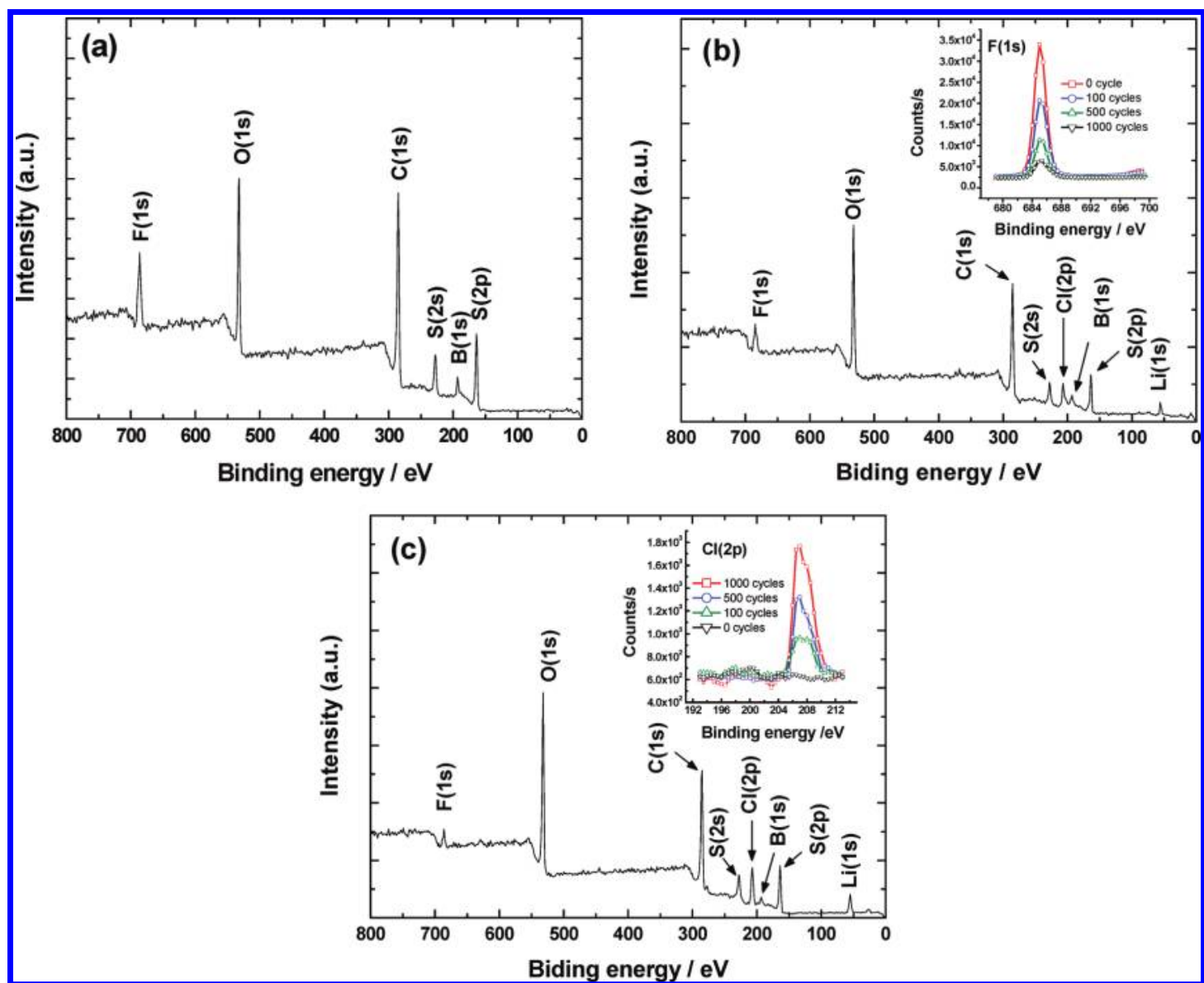

FIGURE 7. Wide-angle XPS scan giving the elemental composition of (a) the as-prepared PEDOT film from $0.1 \mathrm{M} \mathrm{LiBF}_{4}$ Solution, (b) the PEDOT film after $500 \mathrm{CV}$ cycles, (c) the PEDOT film after $1000 \mathrm{CV}$ cycles in $0.1 \mathrm{M} \mathrm{LiClO}_{4}$ solution. Insets: Corresponding $\mathrm{F} 1 \mathrm{~s}$ and $\mathrm{Cl} 2 \mathrm{p}$ signals after various numbers of cycles.

where $\Delta m$ is the change in mass, $\Delta Q$ is the charge accumulated during the redox process, $F$ is the Faraday constant, and $W_{\mathrm{ClO}^{-}}^{-}$is the molar mass of $\mathrm{ClO}_{4}^{-}$. Our results clearly indicate that both positive and negative ions were involved in the charge compensation process.

Figure 5 displays plots of $\Delta m$ against the potential and $\mathrm{CV}$ plots for the PXDOTs scanned between 0.3 and $-0.9 \mathrm{~V}$ in $0.1 \mathrm{M} \mathrm{LiClO}_{4} / \mathrm{DMF}$ during the first 100 cycles. We observed a continuous increase in mass, especially at potentials greater than $-0.2 \mathrm{~V}$. After 100 cycles, the accumulation of mass of the PEDOT film was ca. 1.1 $\mu$ g, arising from the trapping of cations, anions, solvated species, and solvent (39-41). These trapped species suppressed ionic transport, leading to a decreased charge capacity. Although we observed the same trend for PProDOT (Figure 5b), its accumulated mass was much lower $(0.8 \mu \mathrm{g})$ after 100 cycles relative to that of PEDOT, suggesting that the ion exchange process was more reversible in PProDOT because of its more porous morphology. For PProDOT- $-\mathrm{Me}_{2}$ and PProDOT-Et ${ }_{2}$, the increases in mass were only 0.51 and $0.36 \mu \mathrm{g}$, respectively, after 100 cycles (panels c and d in Figure 5, respectively). The irreversibility of PEDOT in the various electrolytes was due to the fact that cations and anions both readily transfer into polymer, but cannot be ejected during the redox process, consistent with the observations reported by Plieth and co-workers (42).
Figure 6 displays the variations in charge capacity, relative to that in the first cycle, of the PXDOTs with respect to the number of $\mathrm{CV}$ cycles (between 0.3 and $-0.9 \mathrm{~V}$ ), up to the 1000th cycle (at a scan rate of $100 \mathrm{mV} \mathrm{s}^{-1}$ ). In each case, we observed a continuous decay in the charge capacity, due to the irreversibility of the ionic transfer process. During the redox process, the PXDOTs underwent charge compensation by the cations and anions. A number of ion pairs transported into each of the polymer films without ejection, as revealed in Figure 5. Once the ion pairs were trapped among the polymer chains, the trapped sites could not receive any other ions to achieve electroneutralization; therefore, the polymer gradually lost its electroactivity. As a result, the charge capacity ratio decayed most seriously for larger increases in mass. Among these polymers, the was the highest for PProDOT-Et ${ }_{2}$; after 1000 cycles in $0.1 \mathrm{M}$ $\mathrm{LiClO}_{4} / \mathrm{DMF}$, its charge capacity ratio was $81.6 \%$-significantly greater than that for PEDOT $(36.1 \%)$.

The trapping of ions during the electrochemical redox reaction was confirmed through XPS analyses of the asdeposited PEDOT film before and after CV cycling in $\mathrm{LiClO}_{4}$ solution (Figure 7). Because the PEDOT films were prepared from $0.1 \mathrm{M} \mathrm{LiBF}_{4} / \mathrm{ACN}$ under an oxidative potential $(1.1 \mathrm{~V}$ vs $\left.\mathrm{Ag} / \mathrm{Ag}^{+}\right)$, the charge compensation was accomplished by anions $\left(\mathrm{BF}_{4}^{-}\right)$during the polymerization process. In Figure $7 \mathrm{a}$, it is clear that the as-prepared film contained $\mathrm{BF}_{4}^{-}$ 

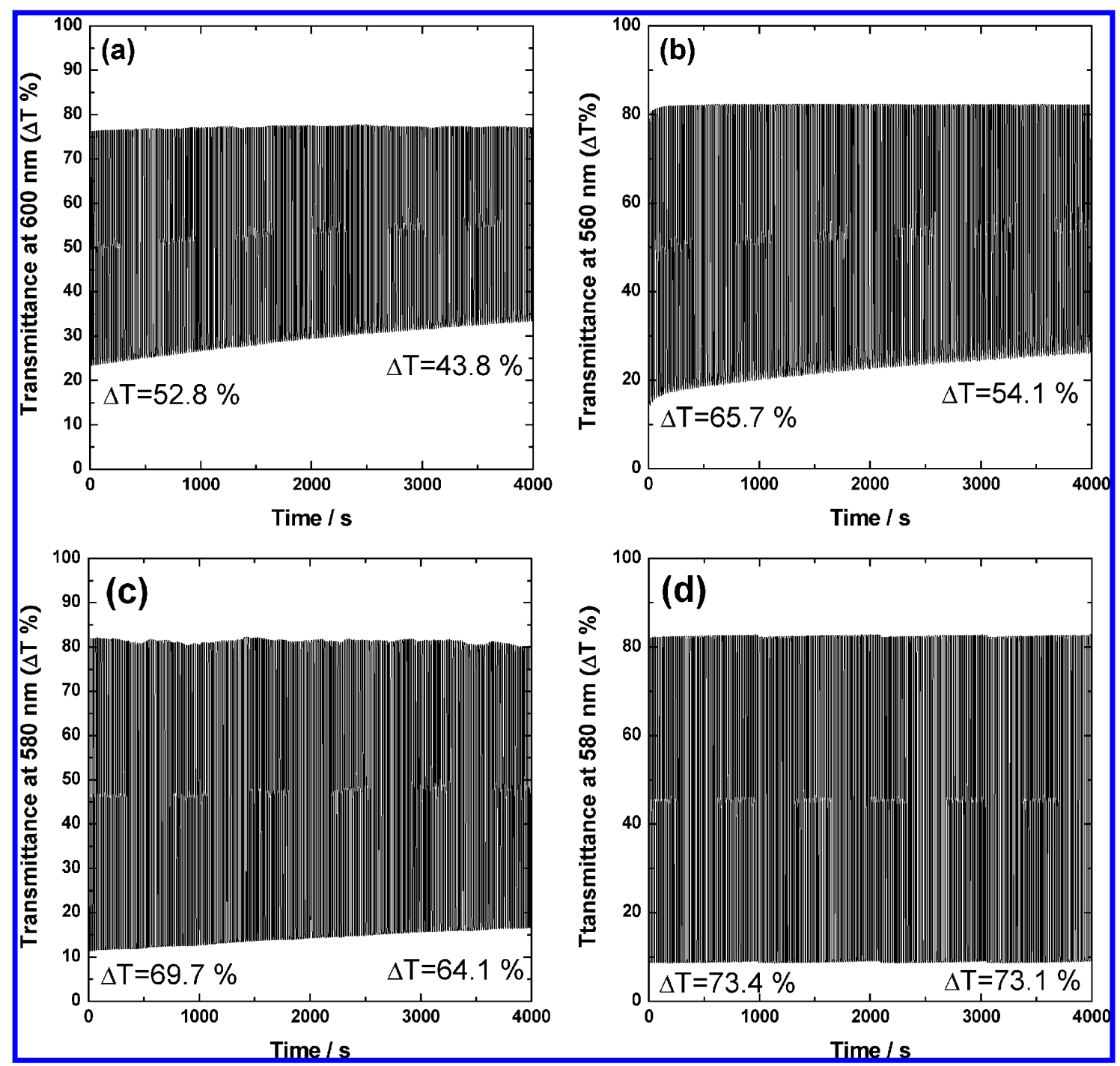

FIGURE 8. In situ transmittance responses of PXDOTs during repeated potential step switching between -0.9 and $0.3 \mathrm{~V}$ in $0.1 \mathrm{M} \mathrm{LiClO}{ }_{4} / \mathrm{DMF}$ : (a) PEDOT, (b) PProDOT, (c) PProDOT-Me ${ }_{2}$, and (d) PProDOT-Et ${ }_{2}$.

counterions because the charge compensation resulted in signals for the F $1 \mathrm{~s}$ and B 1 s energy levels. Furthermore, the intensities of the $\mathrm{Cl} 2 \mathrm{p}$ and Li $1 \mathrm{~s}$ signals increased from 0.05 to 6.7 and from 0.02 to $4.4 \%$, respectively (Figure $7 \mathrm{~b}, \mathrm{c}$ ) after $1000 \mathrm{CV}$ cycles, suggesting that $\mathrm{ClO}_{4}^{-}$replaced the $\mathrm{BF}_{4}^{-}$ counterions within the PEDOT film and that $\mathrm{Li}^{+}$was trapped into the PEDOT film during the continuous redox reaction. The decrease in the signal for $\mathrm{F} 1 \mathrm{~s}$ and the gradual increase for $\mathrm{Cl} 2 \mathrm{p}$ (insets in Figure $7 \mathrm{~b}$,c) after cycling in $\mathrm{LiClO}_{4}$ solution provided further evidence for the trapping of anions and cations during the redox process. Because $\mathrm{Li}^{+}$has a smaller ionic radius (76 pm) than $\mathrm{ClO}_{4}{ }^{-}$(237 pm) (43), and because in general a larger ionic size decreases the mobility, we would expect the amount of trapped $\mathrm{Li}^{+}$to be greater than that of $\mathrm{ClO}_{4}^{-}$. Notably, however, the chemical composition of Li was smaller than that of $\mathrm{Cl}$ after $1000 \mathrm{CV}$ cycles, presumably because of the solvation of the $\mathrm{Li}^{+}$cations. That is, the moving $\mathrm{Li}^{+}$ions were actually highly solvated species, that had larger radii than the $\mathrm{ClO}_{4}{ }^{-}$anions. As a result, the larger solvated $\mathrm{Li}^{+}$ions provided a smaller $\mathrm{Li}$ composition (4.4\%) after 1000 cycles.
In an optical switching study, in which the films were stepped between the oxidized and reduced states, we monitored the percentage transmittance at $\lambda_{\max }$ as a function of time using double potential step chronoamperometry. The spectroeletrochemistry data for the four polymers are provided in the Supporting Information. Figure 8 displays the switching of the PXDOTs between 0.3 and $-0.9 \mathrm{~V}$ at an interval of $10 \mathrm{~s}$ in $0.1 \mathrm{M} \mathrm{LiClO}_{4} / \mathrm{DMF}$. The polymer films were all deposited with a charge capacity of $20 \mathrm{mC} \mathrm{cm}^{-2}$. For PEDOT (Figure $8 \mathrm{a}$ ), we observed a contrast $(\Delta \% T)$ of $53 \%$ at $600 \mathrm{~nm}$. The polymer quite rapidly switched to achieve $95 \%$ of its total optical change in less than $1 \mathrm{~s}$. After 400 double switches in potential in the electrolyte, we observed an attenuation loss in transmittance of $9 \%$. The polymer films featuring more open structures exhibited more stable electrochromic contrasts. The decay in electrochromic contrast after each redox cycle arose from the trapping of ions among the polymer chains, i.e., the irreversibility of ionic transport led to a decay in electroactivity. Thus, the loss in electroactivity observed in Figure 6 resulted from the polymer chains losing their original optical switching capability 
Table 1. Electrochromic Properties of the PXDOTs

\begin{tabular}{llccc}
\hline \multicolumn{1}{c}{ polymer } & $\lambda_{\max }(\mathrm{nm})$ & $\begin{array}{c}\text { contrast, } \\
\Delta T(\%)\end{array}$ & $\begin{array}{c}\text { switching } \\
\text { time, } \tau(\mathrm{s})\end{array}$ & $\begin{array}{c}\text { coloring efficiency, } \\
\eta\left(\mathrm{cm}^{2} \mathrm{C}^{1-}\right)\end{array}$ \\
\hline PEDOT & 600 & 53 & 2.8 & 250 \\
PProDOT & 560 & 66 & 2.3 & 393 \\
PProDOT-Me $_{2}$ & 580,630 & 70 & 1.2 & 580 \\
PProDOT-Et $_{2}$ & 580,632 & 74 & 0.9 & 760
\end{tabular}

after the trapping of ion pairs. We would expect a polymer featuring a more porous morphology to transfer ion pairs more reversibly, thereby providing a more stable long-term electrochromic contrast. Indeed, PProDOT-Et $t_{2}$ exhibited almost completely consistent performance, without decay, indicating that its film was highly stable.

Table 1 summarizes the optical properties of the polymers deposited with a charge capacity of $20 \mathrm{mC} \mathrm{cm}^{-2}$ in 0.1 $\mathrm{M} \mathrm{LiClO}_{4} / \mathrm{DMF}$. We determined the coloring efficiency, $\eta(\lambda)$, measured at $\lambda_{\max }$, defined using eq 1 , from the slope of the plot of the increase in the optical density change, $\triangle O D$, versus the injected/ejected charge as a function of electrode area, $\Delta Q$

$$
\eta\left(\lambda_{\max }\right)=\Delta O D / \Delta Q
$$

We found that the values of $\Delta \% T$ and coloration efficiency $(\eta)$ increased upon increasing the ring size and the length of the substituents, from $53 \%$ and $250 \mathrm{~cm}^{2} \mathrm{C}^{-1}$, respectively, for PEDOT to $66 \%$ and $393 \mathrm{~cm}^{2} \mathrm{C}^{-1}$, respectively, for PProDOT, to $74 \%$ and $760 \mathrm{~cm}^{2} \mathrm{C}^{-1}$, respectively, for PProDOT-Et ${ }_{2}$. This behavior can be explained by considering that a more-open morphology, resulting from bulkier substituents, allowed more dopant ions to be accommodated within the film, thereby forming a more highly doped state (44). Therefore, the PXDOTs exhibited especially high changes in visible transmittance. Not only did the values of $\Delta \% T$ and $\eta$ increase for the porous structures allowing a highly facile ionic transport: these systems also exhibited decreased switching times (Table 1). Notably, all of our polymer films exhibited relatively higher values of $\Delta \% T$ and $\eta$ than those reported previously $(45,46)$, presumably because the polymer chains underwent transitions from compact to extended coils in the presence of DMF. Many groups have reported that similar phenomena lead to increases in the conductivity of PEDOT:PSS (47-51).

\section{CONCLUSIONS}

We have investigated the correlation between charge trapping and the electrochromic performance of PXDOTs. The presence of bulky substitutions increased the porosity of the PXDOT derivatives, thereby reducing the number of ion pairs that remained trapped among the polymer chains after redox processes. This phenomenon imparted the polymers with higher electrochemical and electrochromic stabilities. The porous morphology of PProDOT$\mathrm{Et}_{2}$ allowed it to retain its optical response without obvious decay after 4000 cycles - superior stability relative to that of PEDOT. Moreover, PProDOT-Et ${ }_{2}$ also exhibited a higher coloration efficiency and a shorter switching time.
Acknowledgment. We thank the National Science Council (NSC) of Taiwan (NSC 97-2120-M-002-012 and NSC 982221-E-001-002) and Academia Sinica for financial support.

Supporting Information Available: The spectroeletrochemistry data for the four polymers (PDF). This material is available free of charge via the Internet at http://pubs. acs.org

\section{REFERENCES AND NOTES}

(1) Monk, P. M. S.; Mortimer, R. J.; Rosseinsky, D. R. Electrochromism and Electrochromic Devices: Cambridge University Press: Cambridge, U.K., 2007; ISBN 978-0-521-82269-5.

(2) Groenendaal, L. B.; Jonas, F.; Freitag, D.; Pielartzik, H.; Reynolds, J. R. Adv. Mater. 2000, 12, 481

(3) Groenendaal, L. B.; Zotti, G.; Aubert, P. H.; Waybright, S. M.; Reynolds, J. R. Adv. Mater. 2003, 15, 855

(4) Sallard, S.; Brezesinski, T.; Smarsly, B. M. L.Phvs. Chem. C 2007, 111,7200 .

(5) Deepa, M.; Awadhia, A.; Bhandari, S.; Agrawal, S. L. Electrochim. Acta 2008, 53, 7266

(6) Park, S. Y.; Lee, J. M.; Noh, C.; Son, S. U. L.Mater. Chem. 2009, 19, 7959 .

(7) Niklasson, G. A.; Granqvist, C. G. L.Mater. Chem. 2007, 17, 127

(8) Chernova, N. A.; Roppolo, M.; Dillon, A. C.; Whittingham, M. S. L. Mater. Chem. 2009, 19, 2526.

(9) Blackman, C. S.; Parkin, I. P. Chem. Mater. 2005, 17, 1583.

(10) Jain, V.; Khiterer, M.; Montazami, R.; Yochum, H. M.; Shea, K. J.; Heflin, J. R. ACS Appl. Mater. Interfaces 2009, 1, 83.

(11) Zhang, C. F.; Liu, A.; Chen, M.; Nakamura, C.; Miyake, J.; Qian, D. I. ACS Appl. Mater. Interfaces 2009, 1, 1250.

(12) Kumar, A.; Reynolds, J. R. Macromolecules 1996, 29, 7629.

(13) Welsh, D. M.; Kumar, A.; Meijer, E. W.; Reynolds, J. R. Adv. Mater. 1999, 11, 1379.

(14) Schwendeman, I.; Hwang, J.; Welsh, D. M.; Tanner, D. B.; Reynolds, J. R. Adv. Mater. 2001, 13, 634.

(15) Stenger-Smith, J. D.; Webber, C. K.; Anderson, N.; Chafin, A. P.; Zong, Z.; Reynolds, J. R. L. Electrochem. Soc. 2002, 149, A973.

(16) Welsh, D. M.; Kloeppner, K. J.; Madrigal, L.; Pinto, M. R.; Schanze, K. S.; Abboud, K. A.; Powell, D.; Reynolds, J. R. Macromolecules 2002, 35, 6517 .

(17) Gaupp, C. L.; Welsh, D. M.; Reynolds, J. R. Macromol. Rapid Commun. 2002, 23, 885

(18) Hwang, J.; Tanner, D. B.; Schwendeman, I.; Reynolds, J. R. Phvs. Rev. B 2003, 67, 115205 .

(19) Bhandari, S.; Deepa, M.; Srivastava, A. K.; Kant, R. L. Mater. Chem. 2009, 19, 2336

(20) Bhandari, S.; Deepa, M.; Singh, S.; Gupta, G.; Kant, R. Electrochim. Acta 2008, 53, 3189

(21) Vasilyeva, S. V.; Unur, E.; Walczak, R. M.; Donoghue, E. P.; Rinzler, A. G.; Reynolds, J. R. ACS Appl. Mater. Interfaces 2009, 1,2288

(22) Mortimer, R. J.; Graham, K. R.; Grenier, C. R. G.; Reynolds, J. R. ACS Appl. Mater. Interfaces 2009, 1, 2269

(23) Huang, J. H.; Yang, C. Y.; Hsu, C. Y.; Chen, C. L.; Lin, L. Y.; Wang, R. R.; Ho, K. C.; Chu, C. W. ACS Appl. Mater. Interfaces 2009, 1, $2821-2828$.

(24) Shim, G. H.; Han, M. G.; Sharp-Norton, J. C.; Creager, S. E.; Foulger, S. H. L. Mater. Chem. 2008, 18, 594.

(25) Kumar, A.; Welsh, D. M.; Morvant, M. C.; Abboud, K.; Reynolds, J. R. Chem. Mater. 1998, 10, 896.

(26) Padilla, J.; Seshadri, V.; Filloramo, J.; Mino, W. K.; Mishra, S. P.; Padmard, B.; Kumar, A.; Sotzing, G. A.; Otero, T. F. Synth. Met. 2007, 157, 261

(27) Savvateev, V.; Yakimov, A.; Davidov, D. Adv. Mater. 1999, 11, 519

(28) Wang, J. Y.; Yu, C. M.; Hwang, S. C.; Ho, K. C.; Chen, L. C. Sol.Energ. Mat. Sol. C. 2008, 92, 112

(29) Osaka, T.; Ogano, S.; Naoi, K. J. L. Electrochem. Soc. 1989, 136, 306.

(30) Chang, C. W.; Liou, G. S. Ora. Electron. 2007, 8, 662

(31) Sauerbery, G. Z. Phvs. 1959, 155, 206 
(32) Roncali, J.; Garreau, R.; Yassar, A.; Marque, P.; Garnier, F.; Lemaire, M. L.Phvs. Chem. 1987, 91, 6706.

(33) Mishra, S. P.; Sahoo, R.; Ambade, A. V.; Contractor, A. Q.; Kumar, A. L. Mater. Chem. 2004, 14, 896.

(34) Argun, A. A.; Aubert, P. H.; Thompson, B. C.; Schwendeman, I.; Gaupp, G. L.; Hwang, J.; Pinto, N. J.; Tanner, D. B.; MacDiarmid, A. G.; Reynolds, J. R. Chem. Mater. 2004, 16, 4401.

(35) Reynolds, J. R.; Child, A. D.; Ruiz, J. P.; Hong, S. Y.; Marynick, D. S. Macromolecules 1993, 26, 2095.

(36) Baker, C. K.; Reynolds, J. R. Electroanal. Chem. 1988, 251, 307.

(37) Gaupp, C. L.; Welsh, D. M.; Rauh, R. D.; Reynold, J. R. Chem. Mater. 2002, 14, 3964.

(38) Huang, J. H.; Ho, Z. Y.; Kekuda, D.; Chu, C. W.; Ho, K. C. I. Phvs. Chem.C 2008, 112, 19125.

(39) Hillman, A. R.; Daisley, S. J.; Bruckenstein, S. Phys. Chem. Chem. Phvs. 2007, 9, 2379

(40) Hillman, A. R.; Daisley, S. J.; Bruckenstein, S. Electrochem. Commun. 2007, 9, 1316.
(41) Hillman, A. R.; Daisley, S. J.; Bruckenstein, S. Electrochim. Acta 2008, 53, 3763 .

(42) Plieth, W.; Bund, A.; Rammelt, U.; Neudeck, S.; Duc, L. Electrochim. Acta 2006, 51, 2366.

(43) Ue, M. I. Electrochem. Soc. 1994, 141, 3336.

(44) Krishnamoorthy, K.; Ambade, A. V.; Kanungo, M.; Contractor, A. Q.; Kumar, A. L. Mater. Chem. 2001, 11, 2909.

(45) Sonmez, G.; Meng, H.; Wudl, F. Chem. Mater. 2004, 16, 574.

(46) Gaupp, C. L.; Welsh, D. M.; Rauh, R. D.; Reynolds, J. R. Chem. Mater. 2002, 14, 3964.

(47) Ouyang, J.; Xu, Q.; Chu, C. W.; Yang, Y.; Li, G.; Shinar, J. Polymer 2004, 45, 8443.

(48) Bagchi, D.; Menon, R. Chem. Phvs. Lett. 2006, 425, 114.

(49) Ashizawa, S.; Horikawa, R.; Okuzaki, H. Svnth. Met. 2005, 153, 5.

(50) Huang, J. H.; Kekuda, D.; Chu, C. W.; Ho, K. C. L. Mater. Chem 2009, 19, 3704 .

(51) Hsiao, Y. S.; Whang, W. T.; Chen, C. P.; Chen, Y. C. L. Mater. Chem. $2008,18,5948$.

AM900752M 